\title{
PENGARUH BERBAGAI DOSIS KOMPOS KIRINYUH (Chromolaena odorata) TERHADAP SIFAT KIMIA TANAH DAN HASIL TANAMAN JAGUNG (Zea mays L.)
}

\section{The Effect Of Various Dosage Of Kirinyuh Compost (Chromolaena odorata) On The Chemical Properties Of Soil And Corn Crop Yields (Zea mays L.)}

\author{
Riza Syofiani ${ }^{1}$, Syaifuddin Islami ${ }^{1)}$ \\ ${ }^{1}$ Program Studi Agroteknologi, STIPER Sawahlunto Sijunjung \\ *) Corresponding author: rizasyofiani14@gmail.com
}

\begin{abstract}
'Indonesia's demand for imports of maize is an average of $9 \%$ or 1.4 million tons per year, while the increase in planted area is only $1 \%$ per year. So that this provides a great opportunity for farmers to increase production, it is necessary to increase the yield. Efforts that can be made to increase soil fertility and yield of maize are the addition of organic matter. One of the plants that have great potential as a source of organic matter that can be cultivated is kirinyuh. The composition of the residual nutrient content is $2.42 \% \mathrm{~N} ; 0.26 \% \mathrm{P} ; 50.40 \% \mathrm{C}$; and $20.82 \% \mathrm{C} / \mathrm{N}$. This study aimed to obtain the correct dosage of kirinyuh compost (Chromolaena odorata) on soil chemical properties and yield of maize (Zea mays L.). This study used a completely randomized design (CRD) with 4 treatment levels and 5 replications so that there were 20 experimental units. The dosage for each treatment is given as follows: $K 0=$ control, $K 1=10 \mathrm{t} / \mathrm{ha}, \mathrm{K} 2=15 \mathrm{t} / \mathrm{ha}, \mathrm{K} 3=20 \mathrm{t} / \mathrm{ha}$. The results of the observations were analyzed using the $\mathrm{F}$ test. If $\mathrm{F}$ count $>\mathrm{F}$ table $5 \%$ then proceed with the Duncans New Multiple Range Test (DNMRT) at the 5\% real level. Provision of kirinyuh compost at a dose of $20 \mathrm{t} / \mathrm{ha}$ (K3) can improve soil chemical properties ( $\mathrm{pH}, \mathrm{Al}-\mathrm{dd}, \mathrm{P}$-available, N-total, $\mathrm{K}$-dd) and give the best results on plant growth (corncob length, and the weight of 100 seeds).
\end{abstract}

Key words: kirinyuh, soil chemistry, corn

\begin{abstract}
ABSTRAK
Kebutuhan impor jagung Indonesia rata-rata $9 \%$ atau 1,4 juta ton per tahun, sedangkan kenaikan areal tanam hanya $1 \%$ per tahun. Sehingga hal tersebut memberikan peluang yang besar bagi para petani dalam meningkatkan produksi, maka perlu diusahakan peningkatan hasil. Upaya yang dapat dilakukan untuk meningkatkan kesuburan tanah dan hasil tanaman jagung adalah dengan penambahan bahan organik. Salah satu tanaman yang berpotensi besar sebagai sumber bahan organik yang dapat dibudidayakan adalah kirinyuh. Komposisi kandungan hara kirinyuh $2,42 \% \mathrm{~N} ; 0.26 \% \mathrm{P}$; $50.40 \% \mathrm{C}$; dan $20,82 \% \mathrm{C} / \mathrm{N}$. Tujuan dari penelitian ini adalah untuk mendapatkan dosis kompos kirinyuh (Chromolaena odorata) yang tepat terhadap sifat kimia tanah dan hasil tanaman jagung (Zea mays L.). Penelitian ini menggunakan Rancangan Acak Lengkap (RAL) dengan 4 taraf perlakuan dan 5 ulangan sehingga terdapat 20 satuan percobaan. Adapun dosis tiap-tiap perlakuan yang diberikan sebagai berikut: $\mathrm{K} 0=$ tanpa perlakuan (kontrol), $\mathrm{K} 1=$ Kompos kirinyuh $10 \mathrm{t} / \mathrm{ha}, \mathrm{K} 2=\mathrm{Kompos}$ kirinyuh $15 \mathrm{t} / \mathrm{ha}, \mathrm{K} 3=$ Kompos kirinyuh $20 \mathrm{t} / \mathrm{ha}$. Hasil pengamatan dianalisis dengan mengunakan uji F. Apabila F hitung > F tabel 5\% maka dilanjutkan dengan Duncans New Multiple Range Test (DNMRT) pada taraf nyata 5\%. Pemberian kompos kirinyuh dengan dosis 20 t/ha (K3) dapat meningkatkan sifat kimia tanah ( $\mathrm{pH}, \mathrm{Al}-\mathrm{dd}, \mathrm{P}$-tersedia, N-total, K-dd) dan memberikan hasil terbaik terhadap pertumbuhan tanam (panjang tongkol jagung, dan bobot 100 biji).
\end{abstract}

Kata kunci: kirinyuh, kimia tanah, jagung 


\section{PENDAHULUAN}

Jagung (Zea mays L.) merupakan salah satu tanaman pangan dunia terpenting selain gandum dan padi. Sebagai sumber karbohidrat utama di Amerika Tengah dan Selatan, jagung juga menjadi sumber pangan alternatif di Indonesia. Penduduk di Indonesia khususnya di Madura dan Nusa Tenggara menggunakan jagung sebagai sumber makanan pokok. Selain sebagai sumber pangan, jagung juga dimanfaatkan sebagai pakan ternak.

Dalam beberapa tahun terakhir proporsi penggunaan jagung oleh industri pakan telah mencapai $50 \%$ dari total kebutuhan nasional. kebutuhan impor jagung Indonesia rata-rata $9 \%$ atau 1,4 juta ton per tahun, sedangkan kenaikan areal tanam hanya $1 \%$ per tahun. Sehingga hal tersebut memberikan peluang yang besar bagi para petani dalam meningkatkan produksi, maka perlu diusahakan peningkatan hasil. Hal tersebut dapat ditempuh dengan jalan memperluas pemakaian bibit unggul, mengintensifkan pemakaian pupuk disamping perluasan areal untuk pertanian jagung di daerah tertentu.

Pada saat sekarang ini, penggunaan pupuk buatan masih sangat tinggi, sementara itu harga pupuk masih tergolong mahal dan untuk mendapatkannya sangat susah. Penggunaan pupuk buatan yang berlebihan atau terus menerus tanpa diimbangi dengan pemberian bahan organik akan berdampak buruk bagi kesuburan tanah, mikroba dalam tanah, lingkungan bahkan juga berdampak buruk bagi manusia. Salah satu upaya untuk meningkatkan kesuburan tanah dan mengurangi dampak buruk terhadap lingkungan adalah dengan penambahan bahan organik. Salah satu tumbuhan yang berpotensi sebagai sumber bahan organik adalah kirinyuh (Chromolaena odorata). Komposisi hara kirinyuh memiliki $2.42 \% \mathrm{~N}, 0.26 \% \mathrm{P}, 50.40 \%$ $\mathrm{C}$, dan $20.82 \% \mathrm{C} / \mathrm{N}$. Daun dan ranting krinyuh dapat dipakai untuk membuat pupuk cair (Jamilah, 2005).

Tujuan dari penelitian ini adalah untuk mendapatkan dosis kompos kirinyuh (Chromolaena odorata) yang tepat terhadap sifat kimia tanah dan hasil tanaman jagung (Zea mays L.).

\section{BAHAN DAN METODE}

Penelitian ini dilakukan di Lahan Sekolah Tinggi IlmuPertanian (STIPER) Sawahlunto Sijunjung. Penelitian ini menggunakan Rancangan Acak Lengkap (RAL) dengan 4 taraf perlakuan dan 5 ulangan sehingga terdapat 20 satuan percobaan. Hasil pengamatan dianalisis secara statistik dengan uji F. Dari hasil analisis bila $\mathrm{F}$ hitung besar dari $\mathrm{F}$ tabel $5 \%$ dilanjutkan dengan uji Duncans New Multipe Range Test (DNMRT) pada taraf 5\%. Penempatan perlakuan dilakukan secara acak, perlakuan yang diberikan dalam penelitian ini adalah:

$\mathrm{K} 0=$ Kompos kirinyuh $0 \mathrm{t} / \mathrm{ha}$ (Kontrol)

$\mathrm{K} 1=$ Kompos kirinyuh $10 \mathrm{t} / \mathrm{ha}$

$\mathrm{K} 2=$ Kompos kirinyuh $15 \mathrm{t} / \mathrm{ha}$

K3 = Kompos kirinyuh 20 t/ha

Data hasil penelitian dianalisis secara statistik dengan uji $\mathrm{F}$ pada taraf $5 \%$. Jika $\mathrm{F}$ hitung lebih besar dari $\mathrm{F}$ tabel $5 \%$, maka dilanjutkan dengan uji lanjutan DNMRT pada taraf nyata $5 \%$.

\section{Prosedur Penelitian \\ Pembuatan Kompos Kirinyuh}

Biomassa kirinyuh dikumpulkan dan dicincang hingga berukuran 3-5 cm kemudian dimasukkan ke dalam drum dengan ketinggian tumpukan $5 \mathrm{~cm}$. Bahan kompos kirinyuh ditaburi dengan kapur dolomit dan diberi larutan EM4 yang di atas permukaan bahan kompos, lalu tambahkan kembali kirinyuh yang sudah dicincang dengan ketebalan dan perlakuan dengan di atas sekitas 2-3 lapisan sehingga seluruh bahan habis digunakan. Tumpukan kompos ditutup rapat dengan menggunakan plastik tebal. Kompos kirinyuh difermentasikan selama 1 minggu. Selanjutnya dilakukan pengadukan 1 minggu sekali selama periode pengom-osan (3-6 minggu) agar seluruh bahan tercampur secara merata.

\section{Persiapan Tempat Penelitian}

Lokasi penelitian terlebih dahulu dibersihkan dari sampah dan gulma yang mengganggu. Persiapan ini dilakukan sebelum penyediaan media tanam. Lahan penelitian dipagar dengan waring dengan luas sesuai kebutuhan lahan yang diperlukan. 


\section{Pemberian Perlakuan dan Penanaman}

Pemberian kompos krinyuh dilakukan sesuai dengan dosis yang telah ditentukan, kemudian diinkubasi selama satu minggu sebelum penanaman. Media tanam dimasukkan ke dalam polybag. Penanaman dilakukan dengan cara membuat lubang tanam pada bagian tengah polybag sedalam $2 \mathrm{~cm}$.

\section{Pemeliharaan}

Penyiraman tanaman dilakukan dua kali sehari pagi dan sore hari kecuali hari hujan, penyiraman juga dilakukan diluar polybag supaya kondisi lingkungan tetap lembab, penyiraman dilakukan dengan hatihati agar tanaman tidak rusak atau patah. Penjarangan dilakukan pada bibit yang tumbuh tidak normal, penjarangan dilakukan setelah tanaman berumur dua minggu setelah tanam agar pertumbuhan tanaman seragam. Penyiangan dilakukan dengan cara manual (dicabut) dengan hati-hati agar tanaman jagung tidak patah dan merusak perakarannya.

\section{Pengamatan}

Parameter pengamatan meliputi pengamatan tanah yaitu analisis sifat kimia tanah seperti $\mathrm{pH}, \mathrm{Al}-\mathrm{dd}$, N-total, Ptersedia, K-dd dan parameter tanaman yaitu panjang tongkol $(\mathrm{cm})$, bobot $100 \mathrm{biji}$ (gram).

\section{HASIL DAN PEMBAHASAN}

\section{Karakteristik tanah sebelum perlakuan}

Berikut hasil analisis tanah sebelum diberi perlakuan. Hasil analisis tanah awal sebelum perlakuan sebagaimana disajikan pada Tabel 1 .
Author(s): Riza Syofiani \& Syaifuddin Islami

Pada hasil sifat kimia tanah, tanah yang digunakan memiliki kesuburan yang rendah. Nilai $\mathrm{pH}$ tanah bersifat masam dengan nilai 5,20. Menurut Riwandi et al., (2014) tingkat kemasaman tanah $(\mathrm{pH})$ yang optimal untuk pertumbuhan dan perkembangan tanaman berkisar antara 5,80-6,20. Hal ini disebabkan oleh kejenuhan Al-dd yang tinggi..

Tabel 1. Hasil tanah awal sebelum perlakuan

\begin{tabular}{lcccc}
\hline \multicolumn{1}{c}{ Parameter } & Nilai & Kriteria(*) \\
\hline $\mathrm{pH}$ & 5,20 & masam & \\
Al-dd & 2,15 & & & \\
N-total (\%) & 0,19 & rendah & \\
P-tersedia (ppm) & 5,47 & rendah & \\
K-dd (me/100g) & 0,16 & rendah & \\
\hline *) (Staf Pusat & Penelitian & Tanah & $(1983$ & cit \\
Hardjowigeno,2003) & & & &
\end{tabular}

Ketersediaan N, P, K juga masih tergolong rendah karena adanya fiksasi oleh Al. Fiksasi tersebut disamping menyebabkan berkurangnya ketersediaan hara dalam tanah juga menyebabkan pemupukan tidak efisien

\section{Pengaruh perlakuan terhadap beberapa sifat kimia tanah}

Pengujian beberapa sifat kimia tanah berupa $\mathrm{pH}$, Al-dd, P-tersedia, N-total, dan Kdd tanah setelah diberi perlakuan dapat dilihat pada Tabel 2 .

pH tanah, Al-dd dan P-tersedia, $N$-total, $K$-dd

Pemberian kompos kirinyuh mampu meningkatkan $\mathrm{pH} \mathrm{H}_{2} \mathrm{O}$ dan peningkatan itu seiring dengan meningkatnya dosis kompos kirinyuh (Tabel 2).

Tabel 2. Hasil analisis pH, Al-d, P-tersedia, N-total, K-ddd tanah setelah diberi perlakuan

\begin{tabular}{clcccc}
\hline Perlakuan & \multicolumn{5}{c}{ Sifat kimia tanah } \\
\cline { 2 - 6 } & $\mathrm{pH}$ & $\begin{array}{c}\mathrm{Al}-\mathrm{dd} \\
(\mathrm{me} / 100 \mathrm{~g})\end{array}$ & $\begin{array}{c}\text { P-tersedia } \\
(\mathrm{ppm})\end{array}$ & $\begin{array}{c}\text { N-total } \\
(\%)\end{array}$ & $\begin{array}{c}\text { K-dd } \\
(\mathrm{me} / 100 \mathrm{~g})\end{array}$ \\
\hline K0 & $5,32 \mathrm{~m}$ & 2,00 & $5,41 \mathrm{r}$ & $0,19 \mathrm{r}$ & $0,15 \mathrm{r}$ \\
K1 & $6,00 \mathrm{am}$ & $\mathrm{Tu}$ & $22,78 \mathrm{sd}$ & $0,32 \mathrm{sd}$ & $0,20 \mathrm{r}$ \\
K2 & $6,08 \mathrm{am}$ & $\mathrm{Tu}$ & $23,11 \mathrm{sd}$ & $0,40 \mathrm{sd}$ & $0,23 \mathrm{r}$ \\
K3 & $6,10 \mathrm{am}$ & $\mathrm{Tu}$ & $26,42 \mathrm{sd}$ & $0,36 \mathrm{sd}$ & $0,25 \mathrm{r}$ \\
\hline
\end{tabular}

Ket : $\mathrm{m}=$ masam, am = agak masam, $\mathrm{r}=$ rendah, $\mathrm{sd}=$ sedang (Staf Pusat Penelitian Tanah (1983 cit Hardjowigeno,2003) tu=tidak terukur

Perlakuan $\mathrm{K} 3$ menghasilkan $\mathrm{pH} \mathrm{H}_{2} \mathrm{O}$ tertinggi yaitu 6,10 jika dibandingkan dengan $\mathrm{K} 0$ dan meningkatkan $\mathrm{pH} \quad \mathrm{H}_{2} \mathrm{O}$ sebesar 0,78 unit. Peningkatan $\mathrm{pH}$ tanah tidak sama setiap perlakuan, dikarenakan dosis kompos kirinyuh yang diberikan 
berbeda-beda masing-masing tanah. Pemberian kompos kirinyuh menyebabkan terjadinya penurunan Al-dd, Kandungan Aldd pada perlakuan $\mathrm{K} 1, \mathrm{~K} 2, \mathrm{~K} 3$ tidak terukur. Jika dilihat pada Tabel 1, perlakuan K0 masih terukur yaitu sebesar 2,00. Penurunan kadar Al-dd karena pemberian bahan organik berupa kompos kirinyuh dan juga berhubungan dengan peningkatan $\mathrm{pH}$ tanah. Pemberian kompos kirinyuh meningkatkan ion $\mathrm{OH}^{-}$di dalam tanah sehingga mampu mengikat Al-dd membentuk senyawa $\mathrm{Al}(\mathrm{OH})_{3}$ yang bersifat mengendap sehingga terjadi penurunan Al-dd. Soepardi (1983) menyatakan bahwa bahan organik dapat mengurangi kelarutan $\mathrm{Al}$ dengan membentuk senyawa komplek yang tidak larut, sehingga hidrolisis $\mathrm{Al}$ menghasilkan ion $\mathrm{H}^{+}$berkurang dan mengakibatkan $\mathrm{pH}$ meningkat.

Ketersediaan $\mathrm{P}$ meningkat karena pemberian bahan organik berupa kompos kirinyuh. Media tanam yang tanpa perlakuan dengan kompos kirinyuh (K0) mengandung P-tersedia 5,41 ppm yang tergolong rendah, setelah diberikan kompos kirinyuh mengalami tren yang terus meningkat + seiring dengan meningkatnya dosis kompos kirinyuh. Prasetyo et al., (2010) menjelaskan bahwa peningkatan ketersediaan $\mathrm{P}$ terjadi karena meningkatnya $\mathrm{pH}$ tanah karena aplikasi bahan organik. Ketersediaan $\mathrm{P}$ maksimum dapat dijumpai pada kisaran $\mathrm{pH}$ antara 5,5-7,0.

Kandungan N-total tanah setelah diberi perlakuan (K1，K2，K3) tergolong kepada kriteria sedang. Peningkatan N-total tanah jelas dipengaruhi oleh pemberian hijauan kirinyuh ke tanah, karena kadar $\mathrm{N}$ kirinyuh yang cukup tinggi yaitu 2,42\% (Jamilah, 2005). Pemberian kirinyuh berperan penting dalam meningkatkan $\mathrm{N}$ total tanah. Gachengo et al., (1999) menyatakan bahwa pemberian bahan hijauan yang cepat melapuk dan memiliki kandungan $\mathrm{N}$ yang tinggi dapat sebagai sumber $\mathrm{N}$ yang efektif bagi tanaman. Peningkatan kadar Ntotal tanah dapat disebabkan oleh pelapukan bahan organik yang meningkatkan aktivitas mikroorganisme. Kandungan K-dd setelah diberi perlakuan yaitu kompos kirinyuh memilki kriteria yang sama yakni rendah. Kandungan K-dd tanah yang diperoleh setelah pemberian kompos kirinyuh dinilai secara kriteria tidak mengalami perubahan, tetapi ada kecendrungan peningkatan seiring dengan pemberian kompos kirinyuh.

\section{Pengaruh perlakuan terhadap panjang tongkol (cm)}

Hasil sidik ragam pengamatan panjang tongkol tanaman jagung pada umur 12 minggu setelah aplikasi berbagai dosis kompos kirinyuh menunjukkan hasil berbeda nyata. Rata-rata panjang tongkol tanaman jagung yang diaplikasikan berbagai dosis kompos kirinyuh pada umur 12 minggu setelah tanam dapat dilihat pada Tabel 3.

Tabel 3. Rata-rata panjang tongkol tanaman jagung yang diaplikasikan berbagai dosis kompos kirinyuh.

\begin{tabular}{cc}
\hline Perlakuan & Panjang tongkol $(\mathrm{cm})$ \\
\hline K0 & $16,00 \mathrm{~b}$ \\
K1 & $19,00 \mathrm{a}$ \\
K2 & $18,33 \mathrm{a}$ \\
K3 & $19,67 \mathrm{a}$ \\
\hline
\end{tabular}

Angka-angka pada lajur panjang tongkol yang diikuti huruf kecil yang sama berbeda tidak nyata menurut uji DNMRT taraf $5 \%$

Dari Tabel 3 dapat terlihat bahwa perlakuan K3 (19,67 cm) menunjukkan pertumbuhan panjang tongkol terpanjang dibandingkan dengan perlakuan $\mathrm{K} 2(18,33 \mathrm{~cm})$ dan perlakuan K1 $(19,00 \mathrm{~cm})$ sedangkan perolehan panjang tongkol terpendek masih terlihat pada perlakuan $\mathrm{K} 0(16,00 \mathrm{~cm})$. Lebih panjangnya ukuran tongkol pada perlakuan K3 dibandingkan dengan perlakuan lainnya, disebabkan karena peningkatan kandungan P-tersedia tanah (Tabel 2).

Kandungan hara $\mathrm{P}$ pada kompos kirinyuh dapat meningkatkan panjang tongkol pada tanaman jagung. Kandungan hara $\mathrm{P}$ pada kompos kirinyuh yaitu 0,26\% (Jamilah, 2005). Peningkatan dosis kompos kirinyuh menyebabkan kadar P-tersedia juga meningkat secara angka. Hal ini menyebabkan perbedaan panjang tongkol pada perlakuan yang diberikan kompos. Fosfor (P) merupakan salah satu pupuk esensial yang dibutuhkan oleh tanaman dalam jumlah banyak, $\mathrm{P}$ berfungsi dalam pembentukan buah, bunga dan biji.

Pengaruh perlakuan terhadap bobot 100 biji (gram)

Hasil sidik ragam pengamatan bobot 100 biji tanaman jagung pada umur 12 minggu setelah aplikasi berbagai dosis kompos kirinyuh menunjukkan hasil berbeda nyata. 
Rata-rata bobot 100 biji tanaman jagung yang diaplikasikan berbagai dosis kompos kirinyuh pada umur 12 minggu setelah tanam dapat dilihat pada Tabel 4.

Tabel 4. Rata-rata bobot 100 biji tanaman jagung yang diaplikasikan berbagai dosis kompos kirinyuh.

\begin{tabular}{cc}
\hline Perlakuan & Bobot $100 \mathrm{biji}$ (gram) \\
\hline K0 & $29,00 \mathrm{c}$ \\
K1 & $34,33 \mathrm{ab}$ \\
K2 & $33,66 \mathrm{~b}$ \\
K3 & $36,66 \mathrm{a}$ \\
\hline
\end{tabular}

Angka-angka pada kolom bobot 100 biji yang diikuti huruf kecil yan sama berbeda tidak nyata menurut uji DNMRT taraf $5 \%$.

Dari Tabel 4 dapat dilihat bahwa perlakuan K3 (36,66 gram) memberikan bobot 100 biji paling tinggi dibandingkan dengan perlakuan K2 (33,66 gram), perlakuan K1 (34,33 gram) dan berat paling rendah terdapat pada perlakuan K0 (29,00 gram). Lebih beratnya perlakuan $\mathrm{K} 3$ dibandingkan dengan perlakuan lainnya disebabkan karena semakin banyak kompos yang diberikan maka semakin banyak unsur hara fosfor (P) yang terserap oleh tanaman untuk pertumbuhan dan perkembangan biji tanaman tersebut. Kandungan hara $\mathrm{P}$ pada kompos kirinyuh yaitu 0,26\% (Jamilah, 2005). Fosfor (P) merupakan salah satu pupuk esensial yang dibutuhkan oleh tanaman dalam jumlah banyak, $P$ berfungsi dalam pembentukan buah, bunga dan biji.

Perkembangan biji dipengaruhi oleh beberapa faktor antara lain varietas tanaman, tersedianya kebutuhan makanan di dalam tanah dan faktor lingkungan seperti sinar matahari, suhu, dan kelembaban udara. Suriatna (1992) mengatakan bahwa kebutuhan unsur hara yang cukup bagi tanaman akan terlihat dari pertumbuhannya yang normal dan kekurangan unsur hara juga terlihat dari pertumbuhannya yang tidak normal.

\section{KESIMPULAN}

Pemberian kompos kirinyuh dengan dosis $20 \mathrm{t} / \mathrm{ha}$ (K3) dapat meningkatkan sifat kimia tanah ( $\mathrm{pH}, \mathrm{Al}$-dd, P-tersedia, N-total, $\mathrm{K}$ dd) dan memberikan hasil terbaik terhadap panjang tongkol $(19,67 \mathrm{~cm})$ dan bobot $100 \mathrm{biji}$ $(36,66$ gr).

\section{DAFTAR PUSTAKA}

Hardjowigeno, S. 2003. Ilmu Tanah. Jakarta. Akdemi Pressindo. 286 hal

Gachengo, C.N., C.A. Palm., B.A. Jama \& C. Othieno. 1999. Tithonia and sauna green manures and inorganic fertilization as phosphorus sources for maize in western. Kenya. Agroforestry system. 44:21-36

Jamilah. 2005. Potensi gulma C. odorata sebagai pupuk hijau dibandingkan $\mathrm{G}$. Sepium yang diberi CMA pada lahan marginal. Prosiding kongres nasional HITI VIII. Tanggal 21-23 Juli 2003. Padang.

Prasetyo, T.B., Yasin, S. dan Yeni, E. 2010. Pengaruh pemberian abu batubara sebagai sumber silika ( $\mathrm{Si}$ ) bagi pertumbuhan dan produksi tanaman padi (Oryza sativa L.). Jurnal Solum 7(1):1-6.

Riwandi, Handajaningsih, M., Hasanudin. 2014. Teknik Budidaya Jagung Dengan Sistem Organik Di Lahan Marjinal. Bengkulu. UNIB Press.

Soepardi, G. 1983. Sifat dan Ciri Tanah. Bogor. Jurusan Tanah Fakultas Pertanian. IPB. 591 hal.

Suriatna. S. 1992. Pupuk dan Pemupukan. PT. Melton putra. Jakarta. 64 hal. 